\title{
Representing IT: Embodying the Electronic Economy
}

\author{
Peter Dobers \\ GRI - Gothenburg Research Institute at Göteborg University, and \\ Industrial Economics and Management at the Royal Institute of Technology \\ (peter.dobers@lector.kth.se • Indek - KTH, 10044 Stockholm, Sweden) \\ Jonathan Schroeder \\ Industrial Economics and Management at the Royal Institute of Technology \\ (jonathan.schroeder@lector.kth.se • Indek - KTH, 10044 Stockholm, Sweden)
}

Paper presented at 16:e Nordiska Företagsekonomiska Ämneskonferensen Uppsala, 16-18 augusti 2001

"Företagsekonomin i kunskapssamhället"

Session 2. IT: knowledge's maid or its master

Chaired by Barbara Czarniawska and Jan Mouritsen

This paper can be viewed and experienced on an interactive version here: http://130.237.51.101/forskning/nff2001/index.html 


\section{Abstract}

The meaning of acronyms such as "IT" or "TIME" is very wide including technologies related to tele- and datacom, information technology, broadband, media and entertainment. Once dealing with digitized information, technologies related to telecom and broadband are often quite abstract and non-tangible-and difficult to represent within marketing communications. How are such technologies represented in communication efforts of major corporations marketing their IT products and services? This paper focus on how IT technologies are represented in increasingly social ways, infusing their materiality with anthropomorphous and cyborg qualities of body and soul. We study the discourse of print, television and radio ads of major corporations involved in current information and communication technologies such as Ericsson, Sony and Telia. The human body and how it functions to represent technology is a central concern, and we draw on recent work in marketing, photography, and management studies to situate bodily images within the marketing of the electronic economy. The paper ends with some speculations on the changing nature of representation in information technology ads, and offers some conclusions about the body as a basic element of communication about invisible products. 


\section{Introduction}

The postindustrial economy is increasingly filled with the production and consumption of "TIME"-related communication technologies in the area of telecom, information technology (IT), multimedia and entertainment. Communication between people and machines, and between machines and other machines, is no new feature when thinking back to the innovation of the telegraph during the 19th century, and the radio and television in the 20th. What is new in the last few decades has been the digitization of information and its increasingly widespread use in the Western world. Of no surprise, we can therefore talk about an electronic economy in today's society.

Up until the mid 1980s, digitized information was presented and represented mainly via text. Early personal computer languages were purely industrial and mechanical, thus non-comprehensible to the everyday user. One had to be precise and write exactly what you wanted to do. The electronic world was based on digits that allowed only two discrete conditions: on or off, " 1 " or " 0 ". The electronic economy's real boom came with the introduction of image based metaphors that brought back non-discrete conditions into the representation of the electronic world. Steve Jobs introduced graphical representation of electronic and digitized information for Apple and Macintosh personal computers in the mid 1980s (Turkle, 1997:34ff; Stephenson, 1999). Marc Andreesen merged the visual realm with the Internet with Mosaic and Netscape software in the mid 1990s. Computer's representing information visually gave "a presence to what novelist William Gibson (1984) termed 'cyberspace'" (Gibson, 1984; Everard, 2000:124). Thus, filling computer screens with eye-catching images and metaphorical pictures became a crucial and prominent tool for delivering and representing information, not only for dealers in trading rooms transferring money at a high volume or for travellers at train stations and airports searching for arrival and departure times (Engeli, 2000). Screens, pictures and images are windows of many different worlds and interesting themes. Sherry Turkle's ground-breaking book Life on the Screen heightened awareness of such universes full of fragmented, diverse and vivid lives and identities (Turkle, 1997).

Another important theme is how IT is represented in the electronic economy through visual images in marketing communications. Our particular focus is on the merger between information technology and the human body, and how such 
cyborgs are represented in ads for a wide range of IT firms. One aim of paper is to present and discuss how magazine, television and radio ads are communicating images by embodying the electronic economy by studying commercial magazine, radio and TV ads on IT products. Such ads open up a window of how the IT is represented in the electronic economy, how such representation is changing and how the human body take up an increasingly central position in such communication and marketing ventures. We start the paper with a brief discussion of representation in marketing communication and then present several illustrative examples of print, radio and television advertisements that incorporate human form to represent disparate features of information technology. We focus on photography - an information technology in its own right - as what Patrick Maynard calls "the engine of visualization" (1999). The body and how it functions to represent technology is a central concern, and we draw on recent work in marketing, photography, and management studies to situate bodily images within the marketing of the electronic economy. The paper ends with some speculations on the changing nature of representation in information technology ads, and offers some conclusions about the body as a basic element of communication about invisible products.

\section{Communications, Representation, Advertisement and Images}

Marketing communication depends largely on visual representation to produce meaning, brand images, and spectacular simulations that create positive associations in consumer's minds. Scholars in marketing, urban geography, management and organization theory have turned to the concept of representation for insight into diverse market-related phenomena, including advertising imagery (Pearce, 1999), war propaganda posters (Hupfer, 1997), research methods (Stern, 1998), photography (Schroeder, 1998), symbolic and entrepreneurial aspects of urban geography (Aase, 1994; Hall and Hubbard, 1998), technology and society (Kallinikos, 1996), corporate environmental management (Mayhew, 1997), and organization theory (Jeffcutt, 1991).

Often, research on representation in advertising focuses on the internal content of advertisements-what the ad claims, how it links the product to consumer benefits, or the design of the ad. These are important issues. However, advertising also acts as a representational system that produces meaning outside the realm of the advertised product (e.g., Goldman, 1992; Leiss, Kline and Jhally, 1999). For example, one of the most important objectives of advertising is the production of taste. Advertising 
serves us as a "lexicon of current cultural meanings" (McCracken, 1987:79). This meaning production contributes to advertising's status as representation.

As representation refers to meaning production through language systems (cf. Stern, 1998), how that language is used is central to creating that meaning. Using representation as an analytic tool, recent studies have emphasized how cultural practice, such as laws, rituals, norms, art, and advertising, all contribute to meaning production within, for instance, marketing (e.g., Hirschman, 1989; Scott, 1994; Firat and Shultz, 1997; Messaris, 1997). Conventional views of representation hold that things, whether object, person, or consumer, exist in the material and natural world, and that their material characteristics define them in perfectly clear terms; representation, according to this view, is of secondary importance in meaning making.

Meaning produced or constructed by social and cultural forces would suggest that representation is of primary importance, however. In this view, representation enters into the very constitution of things, since an object's or idea's meaning is shaped by the very process of representing it by way of language and not simply to the "reconstruction of the world that relies on the schema something for something else" (Kallinikos, 1996:21). Research using this approach has been characterized as falling into two categories, semiotic and discursive (Hall, 1997). Semiotic research, or the poetics of representation, is concerned with how representation produces meaning. Discursive research, or the politics of representation, stresses effects or consequences and connects representation to power and culture (Hall, 1997; Mayhew, 1997). Both types of research—at times overlapping, at times discrete-are necessary for a full examination of representation as meaning producer.

As we will see further below all the advertisements in this paper use the information technology of photography. Sociologists Goldman and Papson point out the close interconnected relationship between advertising and photography:

"(t)he power of advertising lies in its ability to photographically frame and redefine our meaning and our experiences and then turn them into meanings that are consonant with corporate interests. This power to recontextualize and reframe photographic images has put advertising at the center of contemporary redefinitions of individuality, freedom, and democracy in relation to corporate symbols." (Goldman and Papson, 1996:216)

In addition, photography is central to understanding how advertising produces meaning within a circuit of production and consumption of products, services, life ideologies and personal identity. The photographic representations of the 
advertising process ripple through the culture, circulating information about the social world, even the world itself has taken on "a photographic face", as Eduardo Cadava expresses it (Cadava, 1999). What emerges as a significant rippling effect is how these cultural translations become key concerns for ethical reflection on contemporary society.

The approach presented here makes five interrelated assumptions about advertising images. First, ads can be considered aesthetic objects. This assumption acknowledges the creativity and thought that goes into the production of most advertising campaigns, and that consumption has become aesthetized via style, fashion, and integration into what has been called the art-culture system (Lury, 1996). Second, ads are socio-political artifacts. These categories—aesthetic and political—are often constituted as mutually exclusive. Our analysis attempts to locate advertisements within a complex visual signifying system that includes the inter-related domains of the aesthetic and the political. Third, we situate advertising within a system of visual representation that creates meaning within the circuit of culture-often beyond what may be intended by the photographer and advertising agency. Fourth, an interdisciplinary visual analysis does not compete for authority with other approaches. Instead, it stands for a useful, distinct level of analysis, particularly suited to sort out meaning construction in visual images (see Stern and Schroeder, 1994; Bordo, 1997; Schroeder and Borgerson, 1998). Fifth, advertising is a powerful visual medium "that conjoins the world and object between which a transfer of meaning is sought" (McCracken, 1987:79).

In other words, advertising representations are in an interchange with the social and cultural environment. Therefore, they must be understood as the result of changing social and cultural practices. Consequently, our overarching framework views meaning -in advertising as well as art-as the result of historical contingencies. A focus on the social and cultural antecedents for contemporary visual culture illuminates how advertising works visually (cf. McQuarrie and Mick, 1999). Images, which saturated by a long cultural history impart much more than other "nonverbal" media like text (Scott, 1994), constitute an engaging and deceptive visual language. Advertising imagery-as a subset within this system-interacts with it, borrowing from and influencing the larger world of visual culture, just as the electronic economy is represented in different advertisement images.

\section{How the Electronic Economy is Embodied in Advertisement Images}




\section{Magazine Advertisements, technology is entering the body}

A key strategy of contemporary marketing representation is to create a compelling, unique image for a product or service by linking brand names to some aspect of personal or group identity. The human body forms a basic building block of this strategy, reflecting broader concerns about and focus on the body as a central site of representation. Advertising draws on larger pictorial traditions that inform the production and consumption of images. In particular the photographic "depiction of the body has become pervasive in a culture dominated by advertising and Hollywood narrative cinema" (Clarke, 1999:123). In contemporary advertising practice, the body functions as a radiating landmark for innumerable product, social, and emotional attributes ascribed to a vast array of products, services, and ideas. We find it extremely interesting that sophisticated high-tech products increasingly incorporate the ancient, basic human form into their marketing strategy in attempts to physicalize and tangliblize complex, ethereal, and often invisible goods and services.

Several recent print ads, collected from popular magazines such as the Economist, Wired, and Time, provide compelling evidence of the body's communicative role in marketing information technology. The focus on the body seems to exemplify the extending capacity of IT-shifting time and space to allow humans to communicate in spectacular ways. IT expands our cognitive, physical, perceptual, and intellectual abilities—a key theme of current ad campaigns.

For example, Ericsson has a series of ads that feature nearly nude bodies, painted blue, that reveal a network of circuits, cables, and computer chips integrated into the body's skin. "Designer technology" states one ad that portrays a bald headed woman, crouching with her palms resting on the floor, knees splayed out, staring blankly into the camera (see Illustration 1). Her pose is amphibious--she resembles a big blue frog, with the curious addition of computer circuits morphed onto her skin. Her fingers are spread out widely, making further associations to a wet, web-footed frog or salamander. She has no body hair, her blue colored skin is smooth and shiny. She seems ready to leap out of the picture's frame and onto a laptop lily pad. The ad thus juxtaposes an older biological form-amphibians-with a futuristic cyborg form. Ericsson's designer technology, then, offers a vision of the future-a future ushered in by bodily incorporation of technology. IT, in this image, provides the evolutionary link from a more 'primitive' lifeform to 'advanced' cyborg lifestyles. Humans are positioned somewhere in the middle, between frogs and future. 


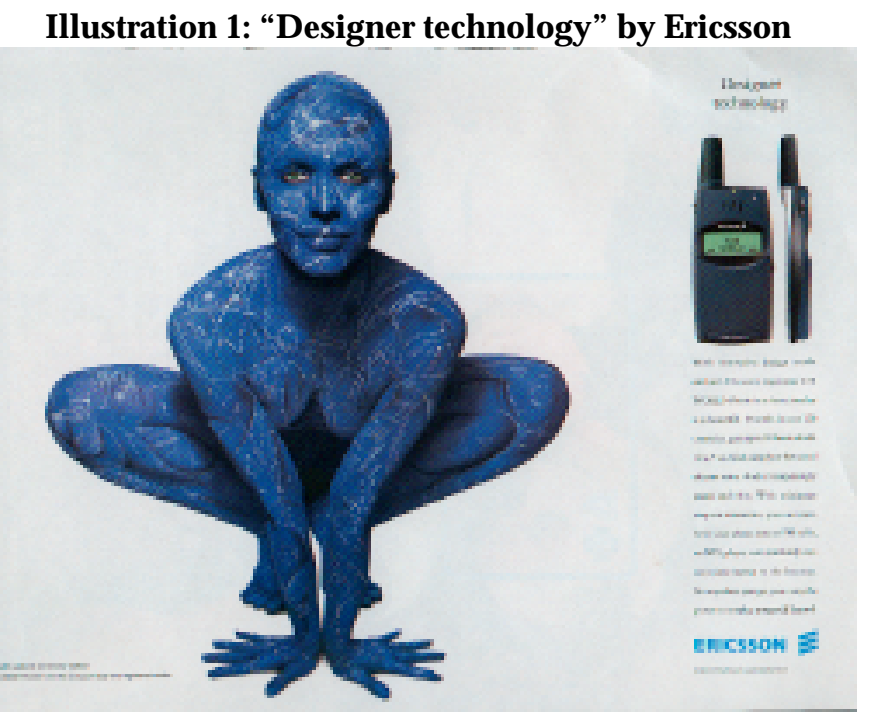

Sony ran a series of ads called "Thing IT", "See IT" and "Hear IT" that offer unique visions of the extending power of IT for human bodies (see Illustration 2). Each blue tinted ad featured a close-up portrait of a young man or woman with an intriguing anatomical addition-one reveals the back of a man's head with a built-in disk drive, another shows a women with camera lenses for eyes, and a third depicts a classic profile portrait of a woman with a compact disk player that has become part of her ear. These ads, that promote a general image of Sony digital technology, suggest that basic human perception might be improved via information technology-a data drive backs up our brain, a stereo system amplifies our hearing, and camera lenses assist our vision. Furthermore, they represent the ultimate corporate incorporation-brands into bodies, and bodies as brands.

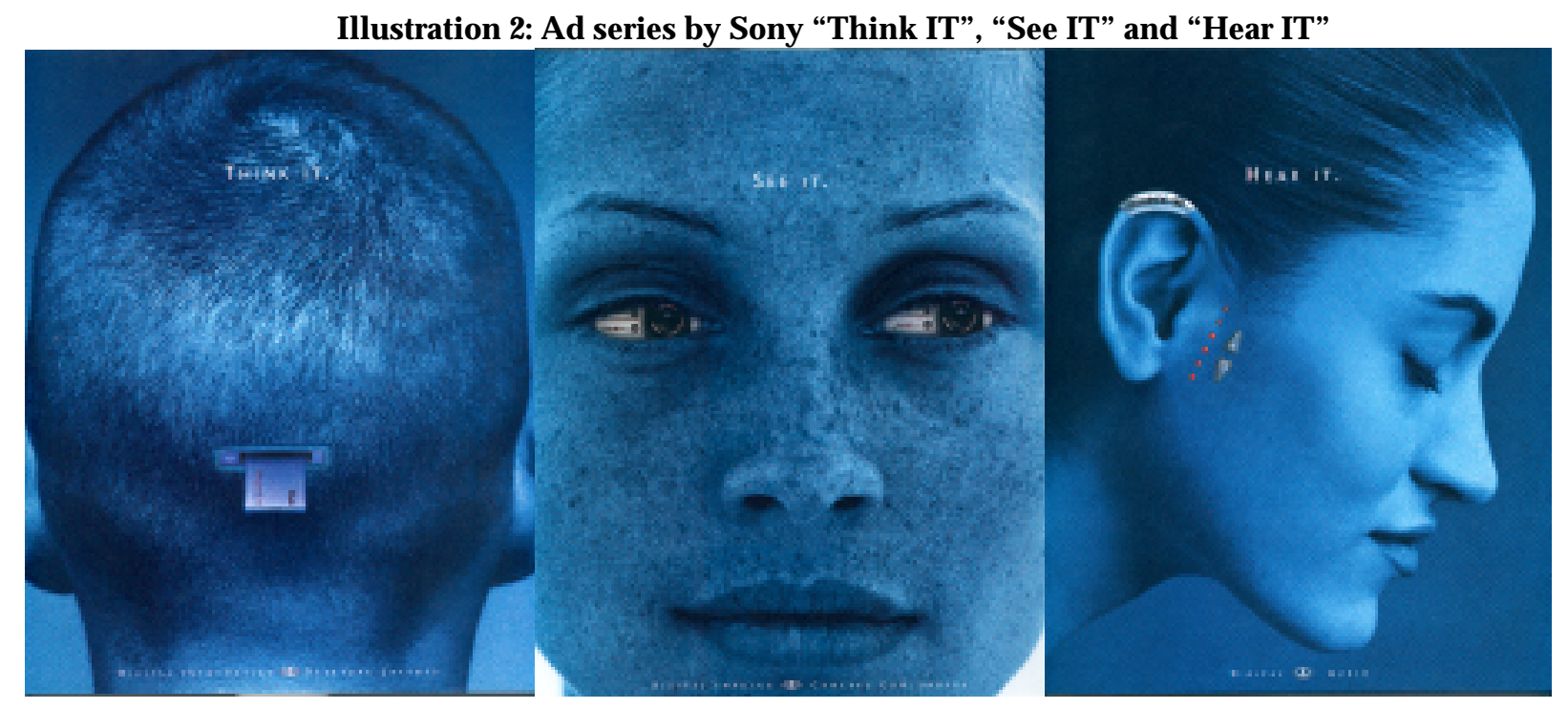


Compaq computers takes up this theme with its "Intelligent? Try ingenious" ad that shows a row of laboratory specimen jars lined up on glass shelves (see Illustation 3). The jars all appear to contain preserved human brains-except one that displays a (rather small) computer. Pushing the man as machine metaphor, this ad gamely attempts to associate computing power with increased intellectual firepower, and, at the same time, humanize computers by representing one as a biological artifact. Of course, the computer remains an imperfect model of the brain, and computers have not displayed organic intelligence of genius-yet. Compaq's brand partner Intel develops biological connections in the ad via its "Intel Inside" tagline- brains are inside, too, just like integrated circuits.

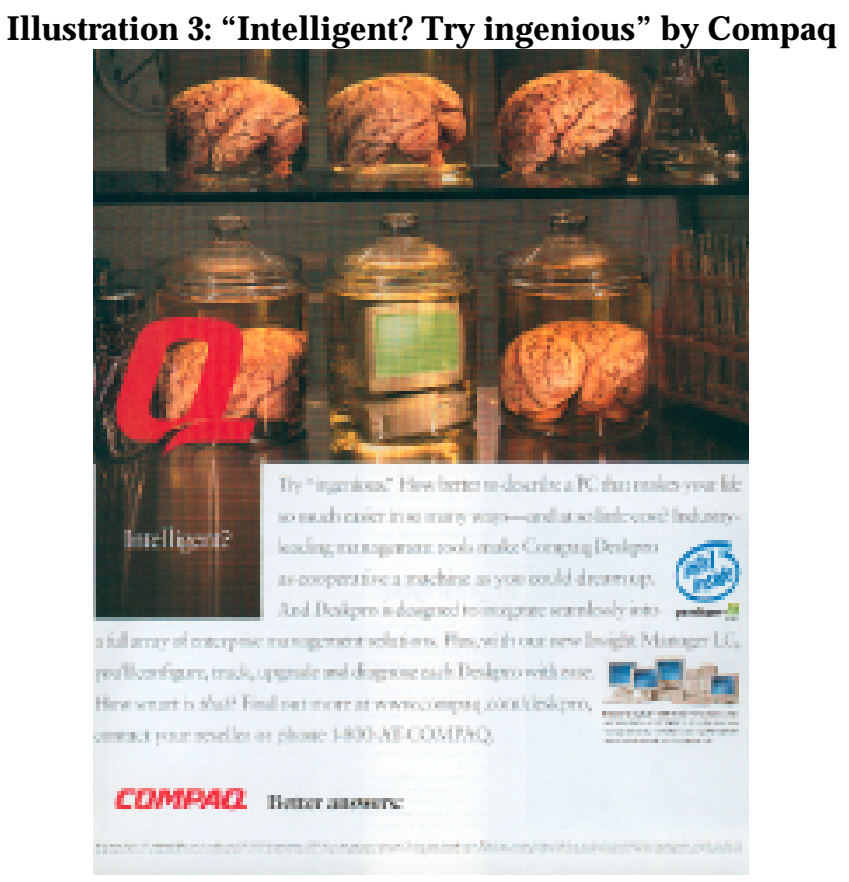

Humans, of course, aren't merely cognitive, perceptual, and information processing systems. We require sustenance, much like computers require electric current. An ad for Sun Microsystems makes a novel, humorous association between the elemental human need to consume food and IT. The ad shows a large man heartily eating hot dogs. One makes his cheeks bulge, another rests in one hand, half eaten, and a third is being picked up by his other hand. The ad reads "Capacity. Sun Enterprise 10000 Server. It consumes data like it's got an iron stomach. Which, of course, it does." So the ad associates capacity for food with capacity for data, human stomachs with diskspace, and performance with physiological processes. This ad is one of the few that revolves around the digestive system, and the only one we have found that portrays a fairly unattractive model. 
Illustration 4: Capacity. "Sun Enterprise 10000 Server.

It consumes data like it's got an iron stomach. Which, of course, it does." by Sun Microsystem

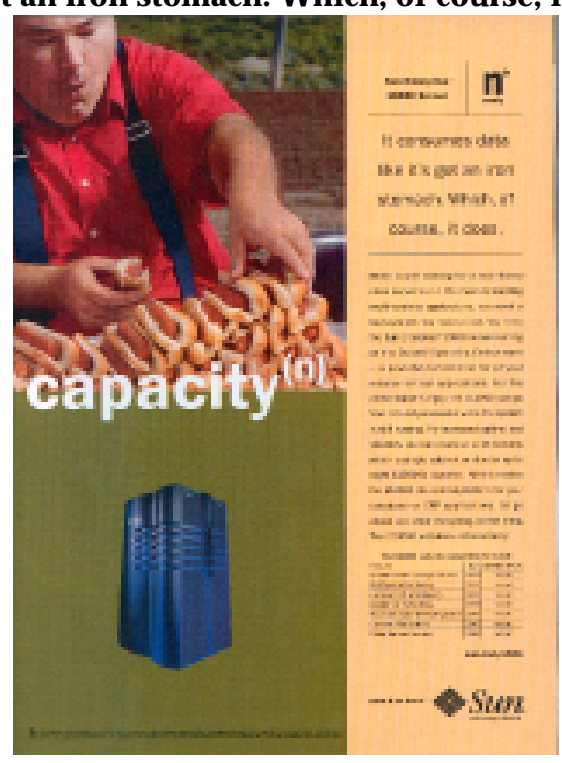

Panasonic's "Life Style" campaign features a middle aged man looking at his hand, which has a small computer screen where his palm ought to be (see Illustration 5). The rectangular screen displays the letters "w@ $\mathrm{p}$ " for wireless application protocol as well as @ for the internet. Once again,we witness the total integration of IT and the human body - no more misplaced phones, palmpilots, or digital devices! The hand is a foundational part of human anatomy, grasping and tool making is a singular characteristic of human life. Panasonic's ad emphasizes the advances possible with WAP technology, and underscores the privilege of symbolic tools over hand tools, data manipulation over physical labor.

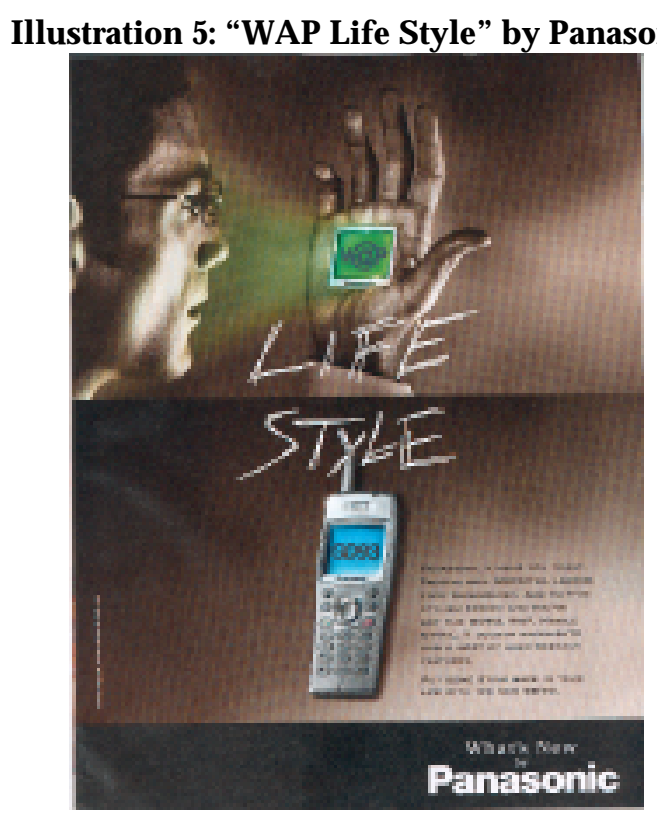


One of our favorites IT images, and one that exemplifies the phenomenon under review, is an ad for GTS "Solutions for a borderless world" (see Illustration 6). This ad has a row of human eyes repeating across the upper part of the image, like a photographic contact sheet, or perhaps an Andy Warhol print. In the center, a large image of the blue, slightly feminine eye gazes out at the viewer. Upon closer inspection, one sees that the eye's pupil is made up of rows of 0 's and 1's-computer language-and also a rough model of how the eye registers light in which neurons fire on or off, responding to the presence of light or movement. The number's presence clearly indicates non-human life, or perhaps cyborg vision. The ad's copy claims that "The Eyes of Europe are on GTS" which is an internet hosting and IT consulting company.

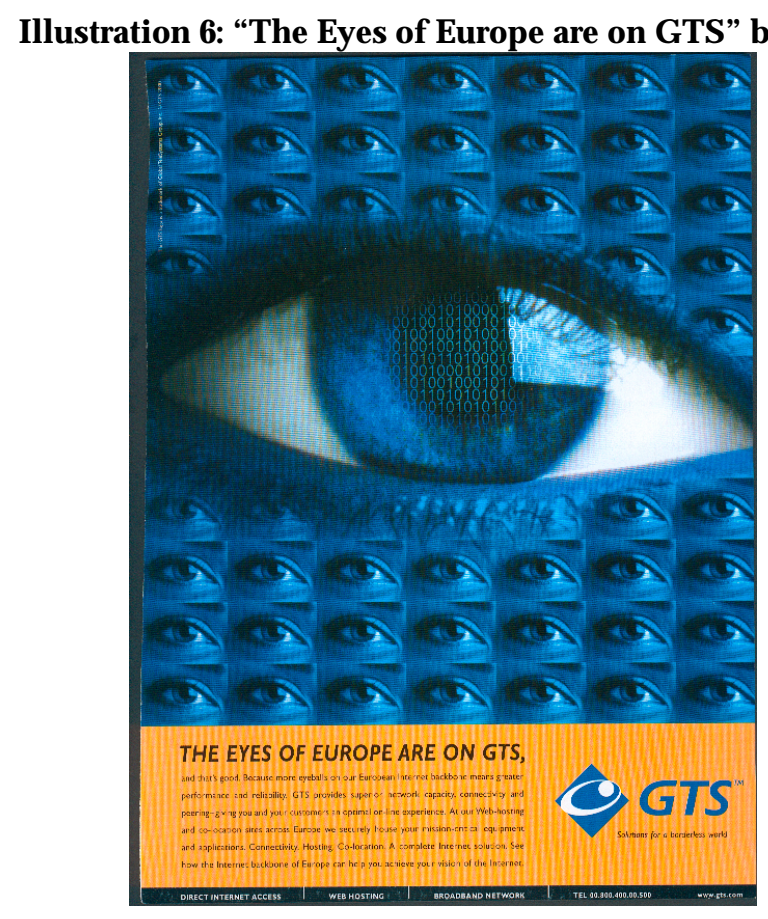

The digitized eyes underscore one of the main promises of information technology - to expand human vision. The internet makes available an incredible, almost infinite amount of visual information available. Moreover, information technology has enabled us to "see" beyond the horizon, beyond the confines of time and space. The GTS image is an icon of IT's potential to digitize, and to standardize information, and to bring visions to our eyes. IT then, extends the human perceptual system in a similar way that earlier information technologies of painting, photography, telescopes and microscopes expanded our visual domain (Maynard, 1999). 
In this image, as in the others discussed further below, IT becomes an essential part of life, indeed, a part of one's body. IT is incorporated into the human body, amplifying its biological capabilities, improving its cognitive capacity, and extending its physical skills. Clearly, IT represents an advance on human traits, these images embrace IT as a seamless, biologically determined solution to human limitations. We are not disputing IT's incredible powers, rather we point to the embodied meaning that these fantastic images connote.

\section{Radio and Television Advertisements, technology is anthropomorphous}

Communication in society has always depended on some kind of infrasystem to carry information over time and space. Today, rune stones and their inscriptions found all over Sweden inform us about the life and adventures of the Scandinavian Vikings, and Italian Renaissance art inform us how Italian patrons benefited from the communicative functions of paintings (Schroeder and Borgerson, 2002). Both examples show how messages from past times communicate with us today and depend on the necessary infrasystem of rune stones and paintings.

One modern infrasystem of the electronic economy is the Internet, which in many ways is invisible to us. The Internet infrasystem is invisible-the fiber optical and copper cables are dug into the ground-but it is also invisible since the information transported on the net is also invisible (Dobers, 2001). However, we never give it a second reflection how this takes place in terms of the transfer of digits through the Internet. Digital information more often than not makes sense when it has arrived after a long travel of e-mails or downloading files or images from the Internet. Depending on the way we access the Internet, up- and downloading of information takes more or less time. Thus, a fast and permanent access to the Internet, through which digits and bits can travel with the speed of light, has become a necessary consumption item to many demanding customers of business and private households.

A bit is the abbreviation of "binary digit" often used when describing storing and transmitting information with an appropriate modem. The most general meaning of bit concerns a binary character that can take the value of " 0 " or " 1 ". It is used to describe storing (memory capacity) and transmission of data or datachunks (speed). A string of 8 bits is called a byte (probably an alteration of bit) and stores information. Sorted in particular ways (for instance 00000000 or 11111111 or any combination of " 1 " and " 0 ") they bear specific meanings coded and decoded by 
computers, and transferred over networks such as the Internet. Nicholas

Negroponte, known for his columns in the Wired magazine, describes a bit this way:

"A bit has no color, size, or weight, and it can travel at the speed of light. It is the smallest atomic element in the DNA of information. It is a state of being: on or off, true or false, up or down, in or out, black or white." (Negroponte, 1995:14)

These digits of " 0 " or " 1 ", as the quotation shows, is a world of discrete values, by which computers process data. The digital world would be rather meaningless to most of us, had there not been a graphical interface that approximates and makes the digital world look-alike the world we experience, the analogue world. ${ }^{1}$ Examples by which these digits are embodied in visible items and give meaning in a represented way to the electronic economy, are radio spots, Internet ads, or TV commercial run by the Swedish tele provider Telia during the year 2000.

Several radio spots describe an ongoing strike regarding the bad working conditions of digits suffering from slow connections to the Internet. Journalists from newsrooms describe the situation in different ways, interviewing individual digits who remain in work or those who already have dropped out. One example is the following 62 second radio ad (see illustration 7, our translation from Swedish).

\section{Illustration 7: "Strike on the Internet" by Telia (Swedish radio commercial, our translation).}

Female news reader in standard Swedish:

"The crisis on the Internet is worsening. An additional 3 million gigabytes have now joined the full-scale strike on the Internet and feelings are very upset. Over to our Internet reporter."

(Background shouts: "Far too slow connections - we need broadband actions"

Reporter with high-pitched voice to overcome the shouts, with Stockholm accent "Yes, here are mp3 files, long mails and game demos side by side, all of them sharing the bad working conditions they no longer want to accept. Dragging downloads and slow connections."

"- I see a binary digit! Excuse me! Excuse me! Why are you here?"

Binary digit with strong Gothenburg accent and slang:

"Because something has to be done!"

Reporter: "What do you mean?"

Binary digit: "We digits are no slaves. Being close to burning out we have to fight the slow connections of people. That is tormenting!"

Jingle in the background:

"Do you also want fast Internet connection?"Check out telia.se/broadband"

${ }^{1}$ Analogue comes from the greek ana logos which means corresponding, symmetrical or conformity and describes change as continuous rather than discrete. Analogue is therefore often used as the oppositve of digital. 
When listening to how the "news" is brought to the radio listener (the aesthetics of the radio ad), the sound and seriousness of the matter is just as if the content would have been true news of our non-electronic world. Instead we hear about the obviously worsening working conditions of "digits" and how they take action and demonstrate. A very human thing to do when the situation calls for it. Digits are embodied and represented by people and makes a technical matter social; a digital matter analogue; and an invisible matter more visible since we can imagine the situation while listening to the radio.

Another example describes the entry of digits into the analogue and material world in which we live. In a series of some 30 short movie clips on their Internet site, Telia describes how five "personalized" digits arrive into the analogue world on several places in Stockholm, maybe after being "zapped" from their City of Bits (Mitchell, 1995). After a long and seemingly risky connection to the Internet, Kicki (a "1") arrives on the lap of the mobile Internet surfer sitting in a café, waiting for connection; Jörgen ( $\mathrm{a}$ " 0 ") arrives in a computer room of a school; and Kurt ( $\mathrm{a}$ " 0 "), Tracy (a " 0 ") and Arash (a " 1 ") arrive at yet different places in and around Stockholm. Some of them rent a car and pick up the other digits to start their roadshow throughout Sweden to mission about broadband and its potentials (delivered by Telia, of course). They travel around to illustrate broadband in many different ways, to distribute leaflets about broadband in Swedish cities, complaining about the analogue development of film when you can take digital pictures and print them immediately, realizing future problems with video stores when you can stream videos in real time on the Internet, and eventually party with other digits from Denmark at the Öresund bridge before leaving the analogue world to "zip" back to the world they belong to, the digital and electronic world.

The last arena for the digits to enter the analogue world is in $6 \mathrm{TV}$ ads that have been aired since summer 2000. All of them concern the working conditions of digits in general and certain digits in particular. First out to hit the TV viewers was a science fiction like setting of a 45 second little film called "The JPEG" (see Illustration 8). 


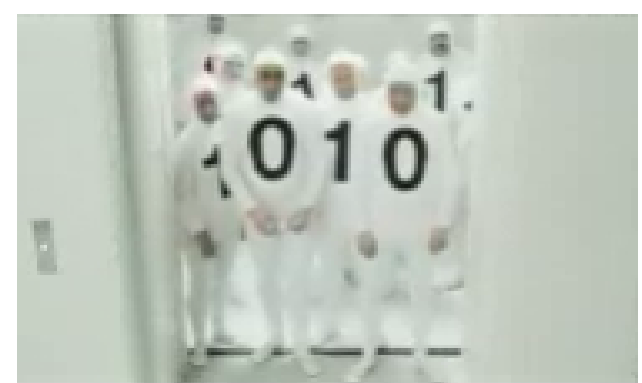

\begin{tabular}{|c|c|}
\hline Setting: & $\begin{array}{l}\text { A man stands elevated on a pedestal and has just overviewed a } \\
\text { departure of some digits. He is in a huge industrial plant that is clean } \\
\text { and white and overlooks a large space in the building. Let us call him the } \\
\text { manager of digital distribution. }\end{array}$ \\
\hline Manager: & $\begin{array}{l}\text { "Goodbye!" } \\
\text { "Next." (A door slides open with a swishing sound and a group of digits } \\
\text { arrive into the building) } \\
\text { "And you are?" }\end{array}$ \\
\hline Digit: & "We're a JPEG, sir. We're going to IP address 195.149.129.195." \\
\hline Manager: & "Allright. That will be gate 42 then." \\
\hline Digit: & $\begin{array}{l}\text { "Right. Brilliant, cheers." (The group of digits start waling towards gate } \\
\text { 42.) }\end{array}$ \\
\hline Manager: & $\begin{array}{l}\text { "Wait! Hold it there! It looks like you've got a slow connection. An old } 28.8 \\
\text { modem." }\end{array}$ \\
\hline Digit: & $\begin{array}{l}\text { "Jesus Christ. Not again! All last night we were downloading for a personal } \\
\text { computer of an old lad." (Many digits shout out loud). }\end{array}$ \\
\hline Manager: & "Yes, I am sorry." \\
\hline $\begin{array}{l}\text { Female digit: } \\
\text { (Chris below!) }\end{array}$ & $\begin{array}{l}\text { "Do you know how it is, do you know how hard it is to work on slow } \\
\text { modems?" }\end{array}$ \\
\hline Manager: & $\begin{array}{l}\text { "Sorry lads. You know the drill."(Major gate opens and digits leave port in } \\
\text { which lights are flickering and they are walking by foot.) }\end{array}$ \\
\hline $\begin{array}{l}\text { Digit in gate: } \\
\text { (text appears or }\end{array}$ & $\begin{array}{l}\text { "Twenty-first century? Ha! More like the Eighteenth century!" } \\
\text { the screen: Telia broadband: telia.se/bredband) }\end{array}$ \\
\hline
\end{tabular}

The episode gives us an overview of a personalized group of digits. We have not only heard the second hand news about the strike on Internet, but here we are gaining a first hand understanding of how terrible the working conditions for digits can be and how fed up they are. When receiving the new destination, the digit sound quite annoyed already ("Right. Brilliant, cheers"). However, when hearing about the slow connection, we witness how upset the group gets, although accepting the situation as is. But it is first in the next two illustration we meet individual digits as they are speaking up at the psychologist in monologue-like manners. It seems that 
individual digits from the JPEG episode are given voice and emotions here (see Illustrations 9 and 10).
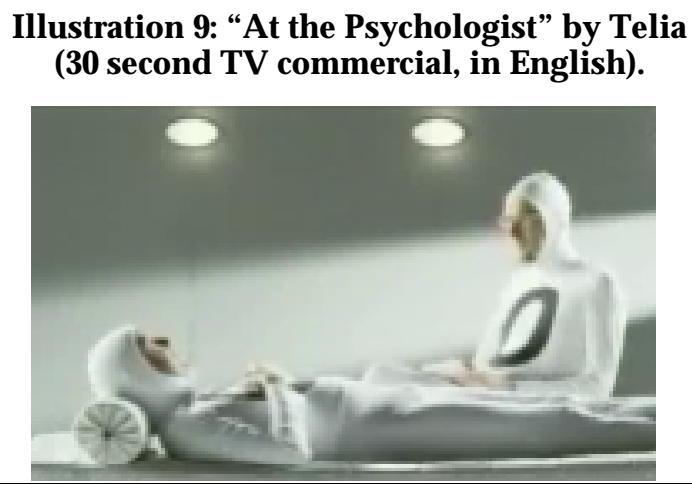

Setting:
One digit lies down on a sofa (patient), and another digit stands up
(doctor).
"Mostly we do e-mails, text files, that sort of stuff. You know, I feel I got
potential you know. I mean, I should be flying aeroplanes, racing cars, chasing
my mates down the corridor for big machine guns, stuff like that, you know!
(Sigh) - What do they give me? (Huh) Business mail from an insurance
company. (Big sigh. Turns around and looks into the camera and a text
appears on the screen: Download games in a minute:
www.telia.se/broadband). The patient speaks up: "It's a fucking joke
man!"

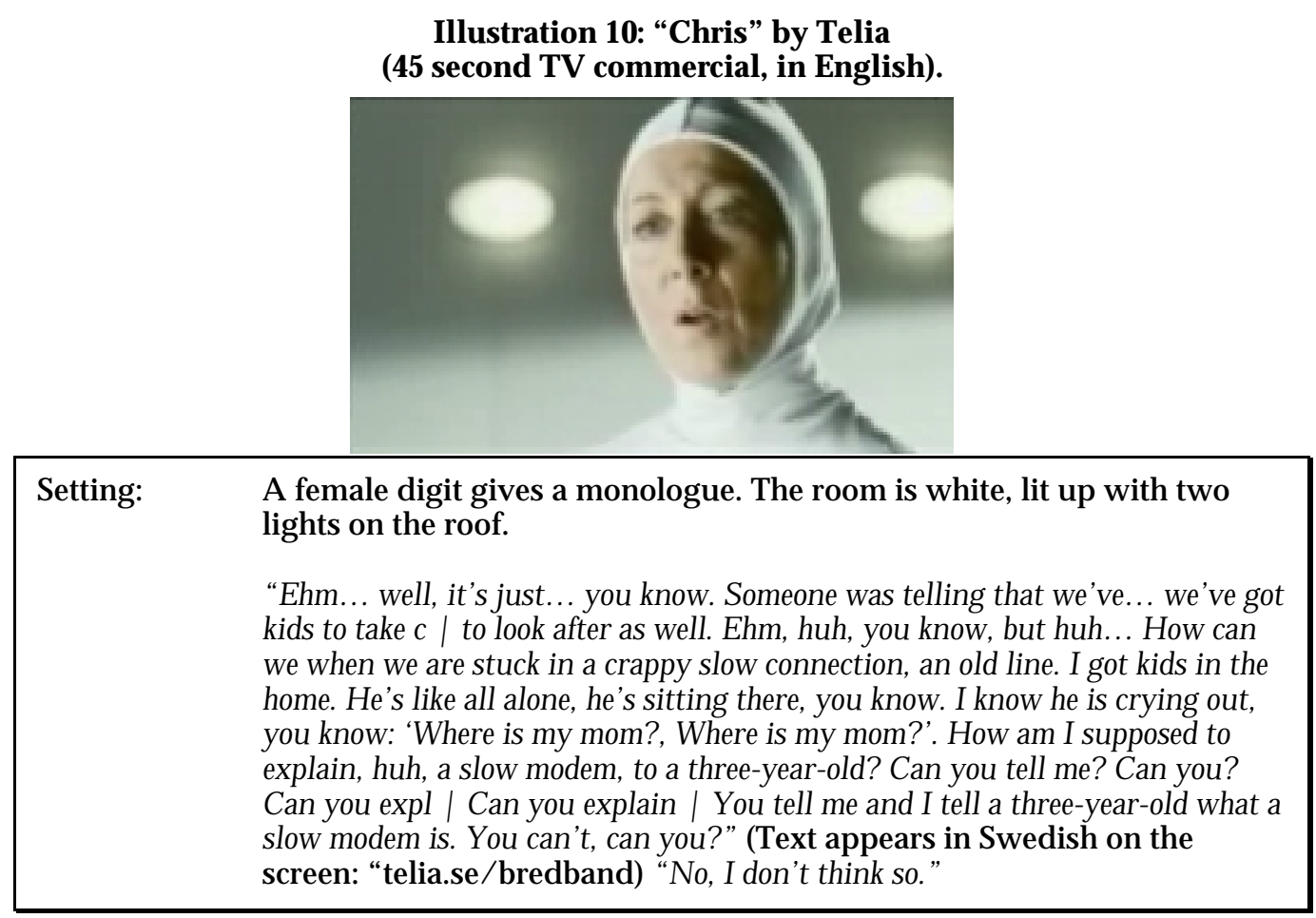


Here we are meeting individual digits in their very personal ways. They are dejected and see no way out of the situation. In typical ways, each digit is given genderspecific characteristics as how society look upon men and women. We have the male digit who rather would like to be involved in computer games than working for a regular insurance company. We have the female digit who rather would like to be with her son, at least spend more time with him.

These ads give a good idea of how the body interacts with information technology, at least in the realm of marketing communications. We think that this is an important arena for study due to its dominant role in informing, persuading, and provoking the general public about IT and the products and services that promise to usher in the future. We have seen several human systems-from digestion to transportation-recruited to tell the spectacularized story of information technology in a way that connects something each of us knows-our bodies-with uncertain, new, complex technologies. IT ads, then, draw on commonsense notions of cognitive, physical, perceptual, and emotional processes, which in turn have been influenced by information processing and artificial intelligence as metaphors for understanding human life.

\section{Discussion}

All these illustrations show how the electronic economy is infused with anthropomorphous qualities to enhance our understanding and attachment to digital information and communication technology. An invisible and incomprehensible world of the digits is given meaning in sense-making episodes (Weick, 1995). Just like saying: "After all, these digits have the same bad working conditions as anyone else in this society. Let's help them by getting broadband connections to our homes or WAP in our hands." The illustrations of the radio and television ads describe waiting time caused by slow connections to the Internet like modems ${ }^{2}$. The personified digits are tired of waiting and waiting therefore becomes a problem. Those digits are translations of a situation to which there are no actor that can speak up by themselves (Latour, 1993; Latour, 1996). Instead, the commercial company Telia takes on an intermediary task to give voice to the otherwise silent digits to represent silent voices and technologies of the electronic economy. Regardless of their commercial interest in this issue, Telia gives voice and meaning

\footnotetext{
2 Modem is put together from the words modulator-demodulator.
} 
to an invisible part of the electronic economy, to a situation otherwise incomprehensible.

These illustrations create meaning by linking up with mundane and trivial issues that people can identify with: overloaded jobs resulting in exhaustion and explaining difficult issues to children. Chris, for instance, is depressed, and would cheer up if she only could work with fast broadband access. However, those poor digits cannot influence their own situation, but the audience to the radio spots and TV ads can by consuming broadband access to the Internet. To describe something intangible and invisible as digital information we need to make reference to something else. In this case, something else of the digits the radio and television ads is represented in our world by human beings. These metaphors of humans give sense to a senseless and invisible electronic and digital world. The graphical interface of today's computers, and the screens with growing resolutions, play an important role in the translation or representation from the analogue world to the digital world. Data by itself can be based on digital rather than analogue media. However, since we live in an analogue world, full of atoms and not full of bits, eventually we need analogue information to reach our senses. Digitally stored music on compact discs have been around for more than 15 years by now. But to reach our ears and to touch our senses, literally speaking, the digits of the CDs must be converted through amplifiers and loudspeakers into analogue sound waves; digits of DVDs or streaming videos over the Internet must be converted on a screen to create images and pictures and waves to reach our eyes and sound waves to reach our ears.

Thus, the graphical interface of computers is a prerequisite for us to make sense of any digitally stored information. A random number of " 0 " or " 1 " won't do us any good, but the translation into sound and changing colors of pixels on the screen, will eventually make sense. Sense making and perception processes remain analogue. A screen, regardless if it's a TV or computer screen, is constructed with many small square dots or pixels (picture elements) as the smallest picture element is called. They are used to construct two-dimensional pictures as we see them on screens (voxels, volume elements, are used to construct a three-dimensional digital picture or sound). When close to screens you will recognize each individual pixel, but when the distance is right, your eye will be fooled to recognize many pixels as a car, or a person. Our eyes accept the approximate representation of the analogue world through the digital medium of a screen and we are fooled to "see" a car or a person. People in real life, as represented by digits in the computer and translated into changing pixels on the screen, do not need any analogies from the digital world to be 
understood, because the digital approximation represent satisfactory the physical or analogue world. However, this separation between the components of the electronic world is blurred and disappears in the magazine ads, and illustrates how advertisement is creating meaning through representation.

In a society so much defined by the logic of the media culture advertising has emerged as a massed site of cultural production and consumption. Despite advertising's working through and within historical classifications and categories of culture, it filters representational conventions of high art "down" to a democratic level of interpretation. It is thus a product and producer of an almost totalizing aesthetic and formal system of representation by virtue of which the viewers' gaze becomes culturally and socially informed. ${ }^{3}$ Advertising's powerful role in successfully producing and diffusing cultural messages of consumption is only amplified, as the viewer is able to link representations to his or her everyday material existence. Thus, reading advertising becomes a cultural practice that allows a maximum of individuals to participate in the process of perception, interpretation, and distinction, because almost everyone possesses the cultural competence to do so.

Representations-including marketing representations--produce meaning on the level of the sign (Barthes, 1967). Language is the central system of representation within which cultural practices-such as laws, rituals, norms, art, and advertising — contribute to meaning production (Hall, 1997; Schroeder, 2002). Therefore, as a pervasive form of communication, advertising discourse both reflects and creates social norms. As one critic points out:

"the ways in which individuals habitually perceive and conceive their lives and the social world, the alternatives they see as open to them, and the standards they use to judge themselves and others are shaped by advertising, perhaps without their ever being consciously aware of it" (Lippke, 1995:108).

Representations help construct reality and are part of the lived experience-these IT images are an important part of the efforts to sell IT throughout the world as a progressive component of an advanced way of life.

3 Note that we limit our use of "totalizing" to the relatively narrow range of possible cultural representations in mass-mediated advertising (Bourdieu, 1998). The result is an almost universal commercial aesthetics. We do not suggest a totalizing effect of advertising representations on the audience as put forth by Horkheimer and Adorno (1993 (1944)). 


\section{Concluding Remarks}

Our intention in this paper was to illustrate how information technology is entering our lives and bodies, as it is represented visually in a wide array of marketing communications. Other studies have suggested that "you are what or where you eat" (Bell and Valentine, 1997:44ff) or that "you are who or what you relate to" (Gergen, 1991; Gergen, 1994). However, we have also shown how the embodied representation of ourselves have given life to the bits and pieces of information technology, as has been visualized by the human-like digits of the television and radio advertisements.

Our body is constantly under pressure to be defined and re-defined by technological development (e.g. Foucault, 1977). In the pre-industrial era, the mechanical and muscular parts of our bodies were extended on a local scale predominantly by different tools, just as the industrial era taught us how to work carefully in a whole system of complex machines and together with other colleagues in factories. In the post-industrial era our minds are extended in space and time through the use of information and communication technologies, and once such technologies have been digitized, it seems as if human bodies to some extent merge with these technologies (compare the similar thoughts in: Woodward, 1994:50).

Are we therefore entering a posthuman era? When considering the change from mere human-machine systems ${ }^{4}$, where humans and machines are apart from and next to each other, our study shows how the human body is situated into and with the electronic world, thus embodying electrons and digits resulting in hybrid or cyborg fabrications of flesh and digits (Haraway, 1991). Efforts with pursuing such cyborg fabrications allow us today to look into genesis and genetics in ways not possible a few decades ago. We can reflect upon artificial life and cyborgs in order to reconsider the life known to us at the present: " $(\mathrm{t})$ he goal of artificial life is to 'model life as it could be so as to understand life as we know it' " (Maes, 1996). In the advertisements of this paper, body and mind is reduced to yet another database to be commercially harvested in the effort to reach imaginative and visual fabrications of information technology.

\footnotetext{
${ }^{4}$ One definition of human-machine system is offered by Lev Manovich: It is "an equipment system, in which at least one of the components is a human being who interacts with or intervenes in the operation of the machine components of the system from time to time" Manovich, Lev, The Labor of Perception. In: Leeson, Lynn Hershman (Ed.) Clicking In. Hot Links to a Digital Culture, (Seattle: Bay Press, 1996), pp. 183-193.
} 
Clearly, boundaries between body and information technologies have become blurred and the viewer of such advertisements are encouraged to see people and bodies as if they were dispersed and fluid systems of flesh and digits. However, when focusing on advertisements as commercial ventures to sell products, such images of cyborg creations become an important tool to gain attention and thereby "holding power" of the viewers and readers of such images and advertisements (Turkle, 1997:30). Images gain in importance when an envisioned embodiment of the electronic economy is communicated; "visible talk" or "graphicspeak" might become the next step in such communication and in the development of information technology (Engeli, 2000:27ff).

\section{References}

Aase, Tor H, Symbolic Space. Representations of Space in Geography and Anthropology, Geografiska Annaler (1994), Vol. 76B, No. 1, pp. 51-58.

Barthes, Roland, Systeme De La Mode (Paris: Edition du Seuil, 1967).

Bell, David and Valentine, Gill, Consuming Geographies. We Are What We Eat (London: Routledge, 1997).

Bordo, Susan, Twilight Zones. The Hidden Life of Cultural Images from Plato to O.J. (Berkeley: University of California Press, 1997).

Cadava, Eduardo, Words of Light. Theses on the Photography of History (Princeton, NJ: Princeton University Press, 1999).

Clarke, Graham, The Photograph (Oxford: Oxford University Press, 1999).

Dobers, Peter, The Digital Invisibility of Broadband and Its Representation in the Modern City. Paper presented at: 97th AAG Annual Meeting, session "The Invisible City" chaired by Maria Kaika, (February 27 - March 3, 2001 in New York, USA: 2001), AAG (Ed.): pp. 227-227.

Engeli, Maia, Digital Stories. The Poetics of Communication (The It Revolution in Architecture), (Basel: Birkhäuser, 2000). Originally published in 1999 by Testo \& Immagine in Turin as "Storie digitali".

Everard, Jerry, Virtual States. The Internet and the Boundaries of the Nation-State (Technology and the Global Political Economy), (London: Routledge, 2000).

Firat, A Fuat and Shultz, Clifford J II, From Segmentation Fo Fragmentation. Markets and Marketing Strategy in the Postmodern Era, European Journal of Marketing (1997), Vol. 31, pp. 1-17.

Foucault, Michel, Discipline and Punish. The Birth of the Prison (New York: Vintage, 1977).

Gergen, Kenneth J., The Saturated Self (New York: Basic Books, 1991). , Realities and Relationships (Cambridge: Harvard University Press, 1994).

Gibson, William, Neuromancer (New York: Ace, 1984).

Goldman, Robert, Reading Ads Socially (New York: Routledge, 1992).

Goldman, Robert and Papson, Stephen, Sign Wars. The Cluttered Landscape of Advertisement (New York: Guilford, 1996).

Hall, Stuart (Ed.) Representation. Cultural Representations and Signifying Practices, (London: Sage / Open University Press, 1997).

Hall, Tim and Hubbard, Phil (Eds.), The Entrepreneurial City. Geographies of Politics, Regime and Representation, (Chichester: John Wiley, 1998).

Haraway, Donna J., Simians, Cyborgs, and Women. The Reinvention of Nature (New York: Routledge, 1991).

Hirschman, E C, Role-Based Models of Advertising Creation and Production, Journal of Advertising (1989), Vol. 18, No. 4, pp. 42-53. 
Hupfer, Maureen, A Pluralistic Approach to Visual Communication. Reviewing Rhetoric and Representation in World War I Posters. In: MacInnis, D and M Brucks (Eds.), Advances in Consumer Research, Vol. 24, (Provo: Association for Consumer Research, 1997), pp. 322-327.

Jeffcutt, Paul, From Interpretation to Representation in Organisational Analysis: Post-Modernism, Ethnography and Organisational Culture. Paper presented at: Towards a new theory of organization, (Keele University: 1991),

Kallinikos, Jannis, Technology and Society. Interdisciplinary Studies in Formal Organizations (Studies of Action and Organization (Sao), Vol. 6), (München: Accedo, 1996).

Latour, Bruno, On Technical Mediation. The Messenger Lectures on the Evolution of Civilization, School of Economics and Management, Lund University, Lund, Working Paper Series of Institute of Economic Research 1993/9, 1993.

_- Aramis or the Love of Technology (Originally published in 1993 as: Aramis, ou l'amour des techniques), (Cambridge, MA: Harvard University Press, 1996).

Leiss, William, Kline, Stephen and Jhally, Sut, Social Communication in Advertising 2nd edition, (Scarborough, Ontario: Nelson Canada, 1999).

Lippke, Richard, Radical Business Ethics (Lanham, Maryland: Rowman \& Littlefield, 1995).

Lury, Celia, Consumer Culture (New Brunswick, NJ: Rutgers University Press, 1996).

Maes, Pattie, Artificial Life Meets Entertainment. Lifelike Autonomous Agents. In: Leeson, Lynn Hershman (Ed.) Clicking In. Hot Links to a Digital Culture, (Seattle: Bay Press, 1996), pp. 210-221.

Manovich, Lev, The Labor of Perception. In: Leeson, Lynn Hershman (Ed.) Clicking In. Hot Links to a Digital Culture, (Seattle: Bay Press, 1996), pp. 183-193.

Mayhew, Nick, Fading to Grey. The Use and Abuse of Corporate Executives 'Representational Power'. In: Welford, Richard (Ed.) Hijacking Environmentalism. Corporate Responses to Sustainable Development, (London: Earthscan, 1997), pp. 63-95.

Maynard, P, The Engine of Visualization. Thinking through Photography (Ithaca, NY: Cornell University Press, 1999).

McCracken, Grant, Culture and Consumption. New Approaches to the Symbolic Character of Consumer Goods and Activities (Bloomington: Indiana University Press, 1987).

McQuarrie, Edward F. and Mick, David Glen, Visual Rhetoric in Advertising. Text-Interpretive, Experimental, and Reader-Response Analyses, Journal of Consumer Research (1999), Vol. 26, No. June, pp. 37-54.

Messaris, P, Visual Persuasion. The Role of Images in Advertising (Newbury Park, CA: Sage, 1997).

Mitchell, William J., City of Bits. Space, Place, and the Infobahn (Cambridge, Massachusetts: MIT Press, 1995).

Negroponte, Nicholas, Being Digital (New York: Alfred A Knopf, 1995).

Pearce, R, Advertising. Critical Analysis of Images. In: Parker, I (Ed.) Critical Textwork. An Introduction to Varieties of Discourse and Analysis, (Buckingham: Open University Press, 1999), pp. 78-91.

Schroeder, Jonathan E, Consuming Representation. A Visual Approach to Consumer Research. In: Stern, Barbara (Ed.) Representing Consumers, (New York: Routledge, 1998), pp. 193-230.

-, Visual Consumption (Interpretative Marketing Studies), (London: Routledge, 2002).

Schroeder, Jonathan E and Borgerson, Janet L, Marketing Images of Gender. A Visual Analysis, Consumption, Markets \& Culture (1998), Vol. 2, No. 2, pp. 161-201.

-, Innovations in Information Technology. Insights from Italian Renaissance Art, Consumption Markets and Culture (2002), forthcoming.

Scott, Linda, Images of Advertising. The Need for a Theory of Visual Rhetoric, Journal of Consumer Research (1994), Vol. 21, No. 3, pp. 252-273.

Stephenson, Neal, In the Beginning Was the Command Line (New York: Avon Books, 1999).

Stern, Barbara B, Introduction. The Problematics of Representation. In: Stern, Barbara B (Ed.) Representing Consumers. Voices, Views, and Visions, (New York: Routledge, 1998), pp. 1-23.

Stern, Barbara B and Schroeder, Jonathan E, Interpretive Methodology from Art and Literary Criticism. A Humanistic Approach to Advertising Imagery, European Journal of Marketing (1994), Vol. 28, pp. 114-132.

Turkle, Sherry, Life on the Screen. Identity in the Age of the Internet (New York: Touchstone, 1997).

Weick, Karl E, Sensemaking in Organizations (Foundations for Organizational Science), (Thousands Oaks: Sage, 1995).

Woodward, Kathleen, From Virtual Cyborgs to Biological Time Bombs. Technocriticism and the Material Body. In: Bender, Gretchen and Timothy Druckrey (Eds.), Culture on the Brink. Ideologies of Technology, (Seattle: Bay Press, 1994), pp. 47-64. 